Article

\title{
Analysing the Effects of Flood-Resilience Technologies in Urban Areas Using a Synthetic Model Approach
}

\author{
Reinhard Schinke ${ }^{1, *}$, Anna Kaidel ${ }^{1}$, Sebastian Golz ${ }^{1}$, Thomas Naumann ${ }^{1}$, \\ José Santos López-Gutiérrez ${ }^{2}$ and Stephen Garvin ${ }^{3}$ \\ 1 Leibniz Institute of Ecological Urban and Regional Development, Weberplatz 1, 01217 Dresden, Germany; \\ Anna.Kaidel@gmx.de (A.K.); S.Golz@ioer.de (S.G.); T.Naumann@ioer.de (T.N.) \\ 2 Universidad Politécnica de Madrid, 28040 Madrid, Spain; josesantos.lopez@upm.es \\ 3 BRE Centre for Resilience, East Kilbride G75 0RD, Scotland, UK; Stephen.Garvin@bre.co.uk \\ * Correspondence: R.Schinke@ioer.de; Tel.: +49-351-4679-295
}

Academic Editor: Wolfgang Kainz

Received: 19 May 2016; Accepted: 17 October 2016; Published: 7 November 2016

\begin{abstract}
Flood protection systems with their spatial effects play an important role in managing and reducing flood risks. The planning and decision process as well as the technical implementation are well organized and often exercised. However, building-related flood-resilience technologies (FReT) are often neglected due to the absence of suitable approaches to analyse and to integrate such measures in large-scale flood damage mitigation concepts. Against this backdrop, a synthetic model-approach was extended by few complementary methodical steps in order to calculate flood damage to buildings considering the effects of building-related FReT and to analyse the area-related reduction of flood risks by geo-information systems (GIS) with high spatial resolution. It includes a civil engineering based investigation of characteristic properties with its building construction including a selection and combination of appropriate FReT as a basis for derivation of synthetic depth-damage functions. Depending on the real exposition and the implementation level of FReT, the functions can be used and allocated in spatial damage and risk analyses. The application of the extended approach is shown at a case study in Valencia (Spain). In this way, the overall research findings improve the integration of FReT in flood risk management. They provide also some useful information for advising of individuals at risk supporting the selection and implementation of FReT.
\end{abstract}

Keywords: built environment; risk assessment and management; flood-resilience technologies; synthetic depth-damage function; flood vulnerability; flood damage modelling

\section{Introduction}

Flood events in the past few decades have shown an increasing intensity and have caused rising economic damage. Principal reasons for the ongoing process are the continuing urban development in flood-prone areas and climate change effects (e.g., [1-4]). They underline the further necessity to improve the resilience of urban areas by suitable flood prevention and flood damage mitigation concepts. In view of the widely used term resilience, it is understood-in the context of the paper-in an engineering perspective as the capacity of the built environment to cope with natural hazards, to prevent or mitigate losses as well as to recover easily and quickly from damaging effects following [5-8]. This is in line with the shift in flood risk management accepting that risks cannot be eliminated completely. Concepts to improve the urban resilience base on more integrative and sustainable approaches considering relevant functions of urban systems and their interactions [9-12]. In consequence, both research and legislation have been reinforcing a more holistic view on each part of the disaster management cycle to improve existing solutions and to develop new options 
reducing current and future flood risks, which also include environmental, societal and economic perspectives [11,13-16].

Within this ongoing process, particularly flood resilience technologies (FReT) on an individual building scale gain in importance. FReT are smart solutions, which refer to any product or material that improves the resilience of the built environment using building aperture technologies, perimeter technologies or building technologies $[7,15]$. During the last decade, the research on FReT includes many advances [17-20], leading to certain guidelines, test procedures, and standard regulations e.g., [15,21-24].

Despite these developments and their potentials, there are obstacles regarding the practical implementation of FReT on a building scale. In this light, White et al. [25] identify (i) a general lack of policy in support of FReT; (ii) a general lack of incentives by key agencies (like public authorities, planners, flood risk managers and insurers) to use FReT; as well as (iii) a reluctance of affected individuals to take responsibility for protecting their properties. Thus, there is a need to increase education, capacity building, and motivation of both professionals and individuals in order to facilitate the uptake of FReT [8,25].

In light of the foregoing, flood damage and risk modelling are playing an important role in analysing potential benefits of FReT implementation. Modelling results support decision makers to evaluate and to prioritise FReT alternatives. In this field, there are several approaches available covering a wide range of assumptions, issues, scopes and model complexities. The review from [26] compared advantages and disadvantages of different approaches and pointed out that stakeholders mainly used simplified approaches, particularly due to minor requirements on any data and knowledge about damage mechanisms. Nevertheless, research activities have promoted additional model developments up to the present with continuously increasing requirements related to the spatial resolution, the understanding and integration of complementary processes, the consideration of additional parameters as well as the reduction of model uncertainty (e.g., [1,7,12,27-29]). These developments underline the importance of a deeper process understanding combined with appropriate data mining and smart simulation algorithms.

The integration of building-related FReT in damage modelling imposes high demands on data and their processing in geo-information systems. It includes a balancing act to analyse overall effects in investigation areas for use by key agencies as well as to provide appropriate information and recommendations for individuals at risk. This could be a further explanation why FReT on building scale are often neglected in flood damage and risk modelling. However, there are some studies analysing potential effects of building-related adaptation strategies. For instance, the authors of [30] analysed costs and benefits of flood precautionary measures for detached single-family houses in order to understand the economic motivation of private households. Critical buildings are in the focus of Escarameia et al. [19]. These buildings are treated as individual cases because of their variety in function, design, and construction. Based on this, the authors present a framework to assess the individual flood vulnerability and to identify measures to improve flood resilience. Poussin et al. [4] investigated the effects of flood damage mitigation strategies in a spatial context by means of land use classes to differentiate the affected area and-based on a literature review-damage reduction factors to consider the effects of flood precautions. The results of the study provide the basis for the assessment of the sensitivity of flood risks to climate and land-use changes as well as to several adaptation options. However, the authors restricted their results to a large geographical scale. Primary reasons are the relatively simple framework with the reduced accuracy of the land-use data at local level.

Against this backdrop, this paper aims to extend an existing synthetic damage model approach in order to assess the effects of building-related FReT in urban areas. It focuses on both the derivation of synthetic depth-damage functions considering well-engineered concepts of FReT and its integration in a spatial context using geo-information systems. The applicability of the approach will be shown by the case study Valencia (Spain). The methodical background provides the damage simulation model called HOWAD with a view to flood impacts $[31,32]$ and GRUWAD with a view to groundwater 
inundation [33], respectively. This GIS-based model follows the source-pathway-receptor-consequence concept (SPRC-concept, [2,34]) and is in line with generalised flood damage and risk assessment procedures (e.g., shown in [12]). The approach facilitates the transferability in different countries demonstrated for Germany [32], United Kingdom [7], and Czech Republic.

Based on the introduction, the paper reflects briefly the overall methodology and highlights the complementary methodical steps integrated in the model approach, which allow the analysis of building-related FReT effects in a spatial context. The results of this extension will be shown with the application in the case study of Valencia. Finally, the discussion and the conclusions will bring together the outcomes of the research work.

\section{Methodology}

The overall concept of the HOWAD/GRUWAD model approach used, encourages the integration of innovative, well-performing methods and the adaptation regarding site-specific issues. It allows damage and risk calculations from local to regional scales. Characteristic features are the calculation of exposure and damage to buildings for every single object by a differentiated view of the urban structure and the building vulnerability. Thus, the model approach is particularly characterised due to high spatial and contextual resolution of the resulting risks. The overall approach has a modular structure with three components to describe the input—flood hazard, urban structure, and vulnerability. The module flood hazards are usually determined by the outcomes of appropriate numerical models that include possible impacts of climate and other natural or anthropogenic changes. The module urban structure characterises the settlement and aggregates properties to building types, distinguishing structure types and construction periods [32,33]. This is why the building type represents a number of buildings with numerous similar attributes such as building size, spatial pattern, mode of construction, and building materials. The similarity within one building type leads to corresponding damage pattern and comparable cost of damage to buildings by the same flood impact [35]. In addition, the module vulnerability determines potential flood damage to buildings by means of synthetic depth-damage functions $[7,27,32,33,35]$. Related to every relevant building type, the derivation of the function uses a civil engineering knowledge-based identification, selection and an in-depth analysis of characteristic, actually existing buildings. A distinguishing feature of the method is the stepwise virtual flooding of these buildings, which we called building type representatives, and the calculation of refurbishment cost for every flood stage. This procedure can be understood as compressed damage expertises including refurbishment planning [35].

The model concept has continually improved, for instance with regard to assessing the effects of mitigation measures as reduced damage to buildings and to other receptors exposed to risks. Different aspects of this methodical enhancement are picked up in $[2,7,36]$. This paper deals with an extended methodology that includes few complementary methodical steps and a modified parameter set to analyse the effects of object-related FReT. Basically, the implementation of flood mitigation effects focus on the three input components of the model approach (Figure 1). Measures like barriers, polders, flood control channels, and river regulations with a change of flood hazard are taken into account by a modified parameter set of the hydrodynamic modelling considering relevant flood recurrence intervals. Relocation of receptors and resettlement are examples that lead to a change in urban structure considered by a modified building layer of the geo-information system. The effects of object-related FReT are to be considered by the synthetic vulnerability assessment method. Addresses here are some methodical key points regarding the integration of FReT and the transfer of case-by-case solutions into a spatial context using geo-information systems. Figure 2 shows the synthetic procedure to calculate building type related synthetic depth-damage functions, integrating the effects of FReT. The additional steps of the procedure are highlighted with four grey boxes. 


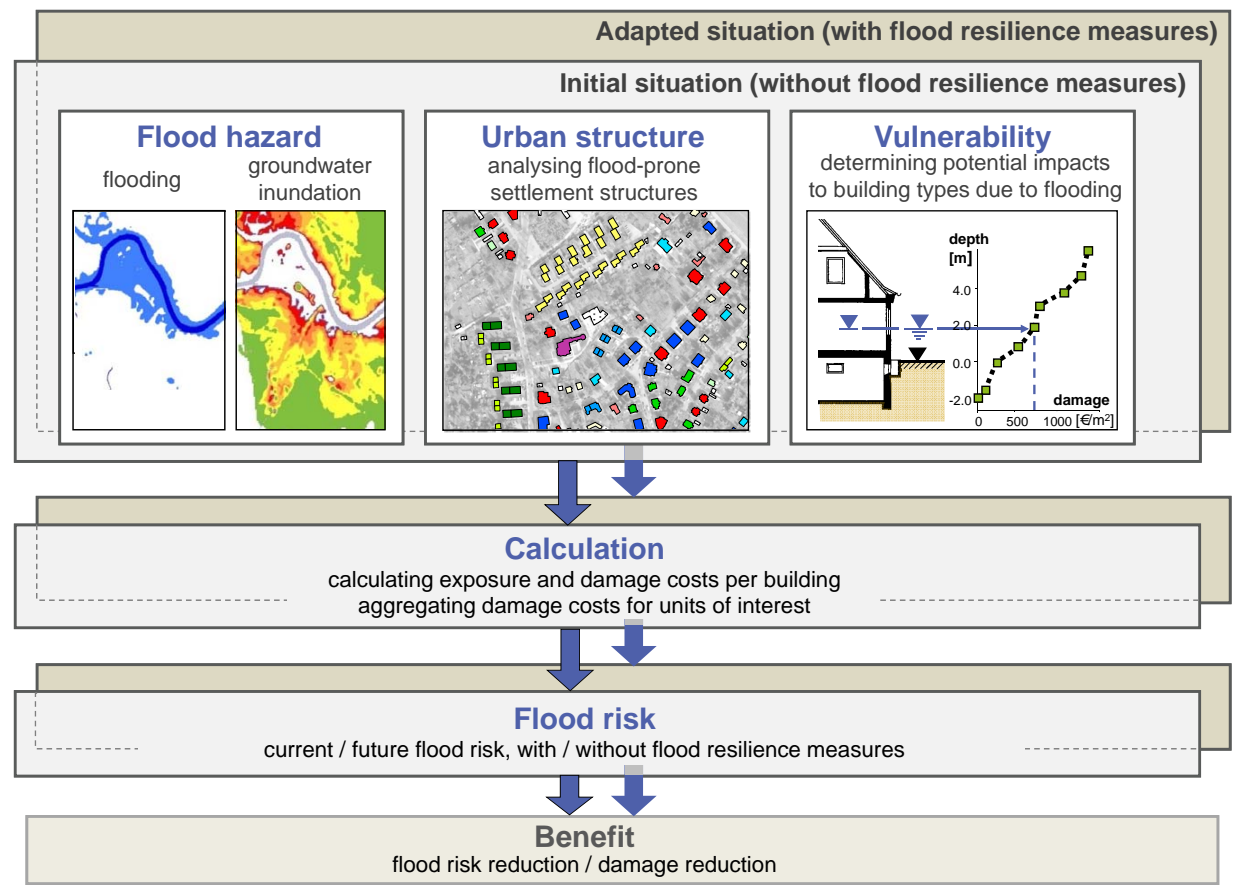

Figure 1. Model approach HOWAD/GRUWAD considering the effects of flood-resilience measures ([32,33], modified).

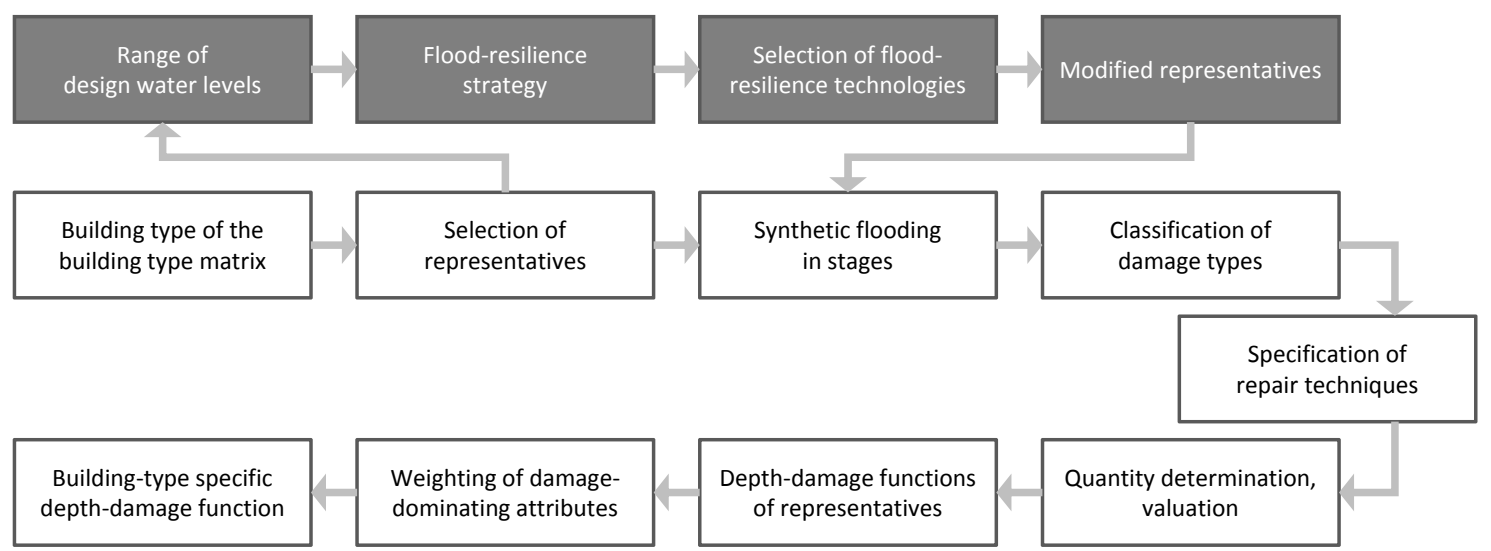

Figure 2. Extended method for calculating synthetic depth-damage functions considering the effects of FReT $([33,35]$, modified).

The integration of building-related FReT indicates an additional investigation of the building type representatives under modified conditions and follows the methodical steps of the synthetic approach. The analysis considers predefined ranges of relevant design water levels. These ranges summarise comparable requirements and solutions regarding FReT integration. Considering important aspects of FReT performance, the limits of the range relate to defined, synthetic flood stages or result in additional stages. Furthermore, the ranges serve as connective links to the exposure of every single building in the investigation area, based on the design flood with its intensity (e.g., recurrence interval, flood water level).

For every range of design water level, the building type representatives need appropriate concepts integrating FReT. The integration process follows the flood-resilience strategies-dry-proofing, wet-proofing, and avoidance, which are closely related to specific FReT. The selection and consideration of the specific measures in the vulnerability assessment are, like the whole procedure, embedded in a civil engineering planning process. 
The planning process focuses initially on well-engineered solutions considering the possibilities and limits of the building type representatives with their characteristic building constructions. In addition, the process allows a continuing optimisation depending on specific issues like efficiency, capability, robustness, sustainability, and so on. It can be used in terms of multi-criteria analysis and investigations of action alternatives. The results are engineering based, appropriate, and generalised FReT concepts for the building type representatives. The adapted buildings are the basis of the following investigation steps, calculating synthetic depth-damage functions.

The transfer of the case-by-case solutions for building type representatives to a generalised, spatial integration of the results need an additional methodical step, which has already been mentioned in [33]. The step is described by weighting of damage dominating attributes and it is used here in terms of the implementation level of FReT. The qualitative effects of this attribute are shown in Figure 3 depending on different flood-resilience strategies.

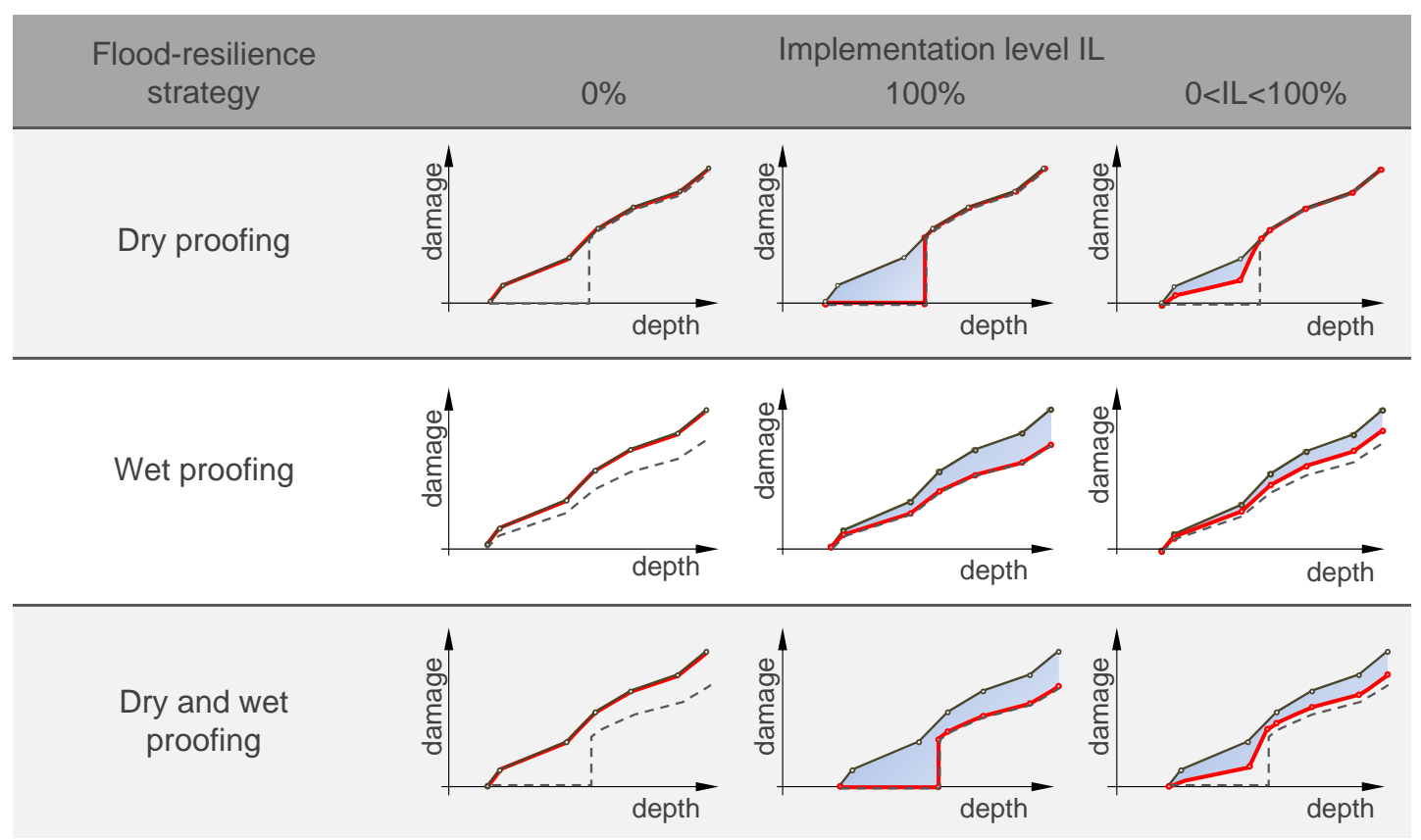

Figure 3. Qualitative effects of the implementation level (IL) as damage dominating attributes depending on selected flood-resilience strategies. Continuous red line: weighted function result; Continuous grey line: implementation level 0\%; Dashed grey line: implementation level 100\%;

Light-blue area: reduced damage as the effect of flood-resilience technologies.

The determination of the implementation level needs corresponding information concerning the investigation area. The information can be specified directly using the building polygon and/or by statistical firm values. The first option is suitable for small study areas or in case of adequate data supply. The second option is the more typical situation. It needs either the specification by field surveys and interviews to cover the present situation or the estimation of predefined target values to assess any planned situation in the future. In summary, the extended concept analyses the risks of the initial and the adapted situations considering FReT. It results in risk reduction that indicates the benefits.

\section{Results of the Case Study Valencia, Spain}

\subsection{Background}

The purpose of the case study is to demonstrate the extended methodology with regard to the analysis of FReT effects. Thereby, the case study of Valencia with its country specific investigation 
serves as the first example to demonstrate the applicability in Spain. This provides basic knowledge to use the damage model approach in further Spanish investigation areas.

Valencia is one of the largest cities in Spain and is situated on the bank of the Turia River, at the east coast of the Iberian Peninsula. The city was often affected by floods of the Turia River. In 1957, the greatest flood occurred, which led to a high loss of lives (officially 81 deaths, 52 within the city area [37]) and heavy loss of properties. Due to the 1957 'cold drop' event with a historical rainfall maximum of $878 \mathrm{~mm} / \mathrm{d}$ at the Xabia station (12th of October, [38]) and the resulting big flood in Valencia, the authorities decided to divert the river towards the south of the city in the1960s, reducing the risk of flooding. However, the Valencia Metropolitan area has been growing southward to the new Turia riverbed. Jucar is the main river in the Valencia plain and is linked to the Turia basin through the 'Albufera' littoral lagoon. Therefore, Valencia's urban area may be affected by flood risks by two sources and paths [39]. In view of the circumstances, the authorities are afraid of further threats to several city areas that are especially

- close to the old Turia riverbed in the case of pluvial and fluvial floods as well as

- close to the Mediterranean Sea in the case of coastal and pluvial floods.

In view of the threats, one of the investigated study areas named Ensanche is close to the historic city centre and covers an area of about 39 hectares $\left(0.39 \mathrm{~km}^{2}\right)$. It is located on the old bank of the Turia River. Figure 4 shows the map of the city with the flood plain of the 1957 event and the study area Ensanche.

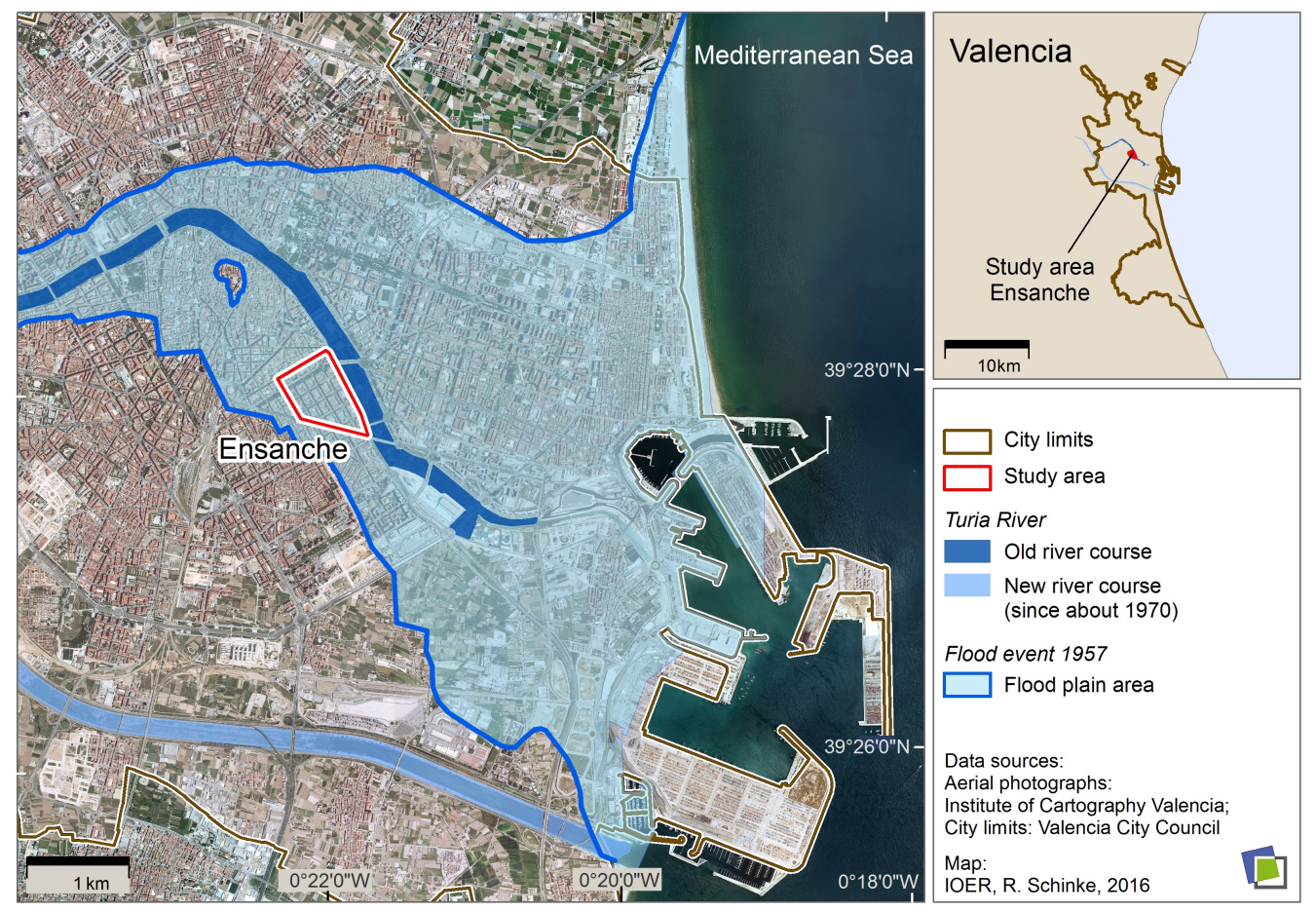

Figure 4. Valencia with the 1957 flood plain and the study area Ensanche.

The current and future hazards of the study area have hardly been explored. This is why the water levels are roughly estimated here using a simplified method and contains numerous uncertainties. However, they serve only as reference values to demonstrate the methodologies. The estimated water levels refer to the 1957 flood event and will approximately correspond with a hypothetical worst-case scenario. They are used here as design flood in terms of the FReT integration. In view of the calculated scenario, the study area is affected by water levels approximately up to $2 \mathrm{~m}$ and low flow velocities. This is why the case study refers to water and/or moisture damage and excludes structural damage to buildings. 


\subsection{Building Typology of the Case Study Valencia}

The characterisation of the urban area follows the building type approach. It needed a derivation of typical Spanish construction periods. These periods reflect the time-dependent, gradual development of the country considering political, architectural, and technical aspects. The derived construction periods and structure types generate the building type matrix as a basis to specify the urban structure in the Spanish study areas. The resulting building type matrix is comparable with findings of [40-42] that increase the connectivity of the research. The developed matrix for the residential buildings was the basis for analysing the settlement structure within the study areas. The detailed analysis with its site-specific outcomes is presented in Figure 5. It comprises the building type map for the study area Ensanche as well as the resulting building type matrix including the fraction of building footprints for every building type.

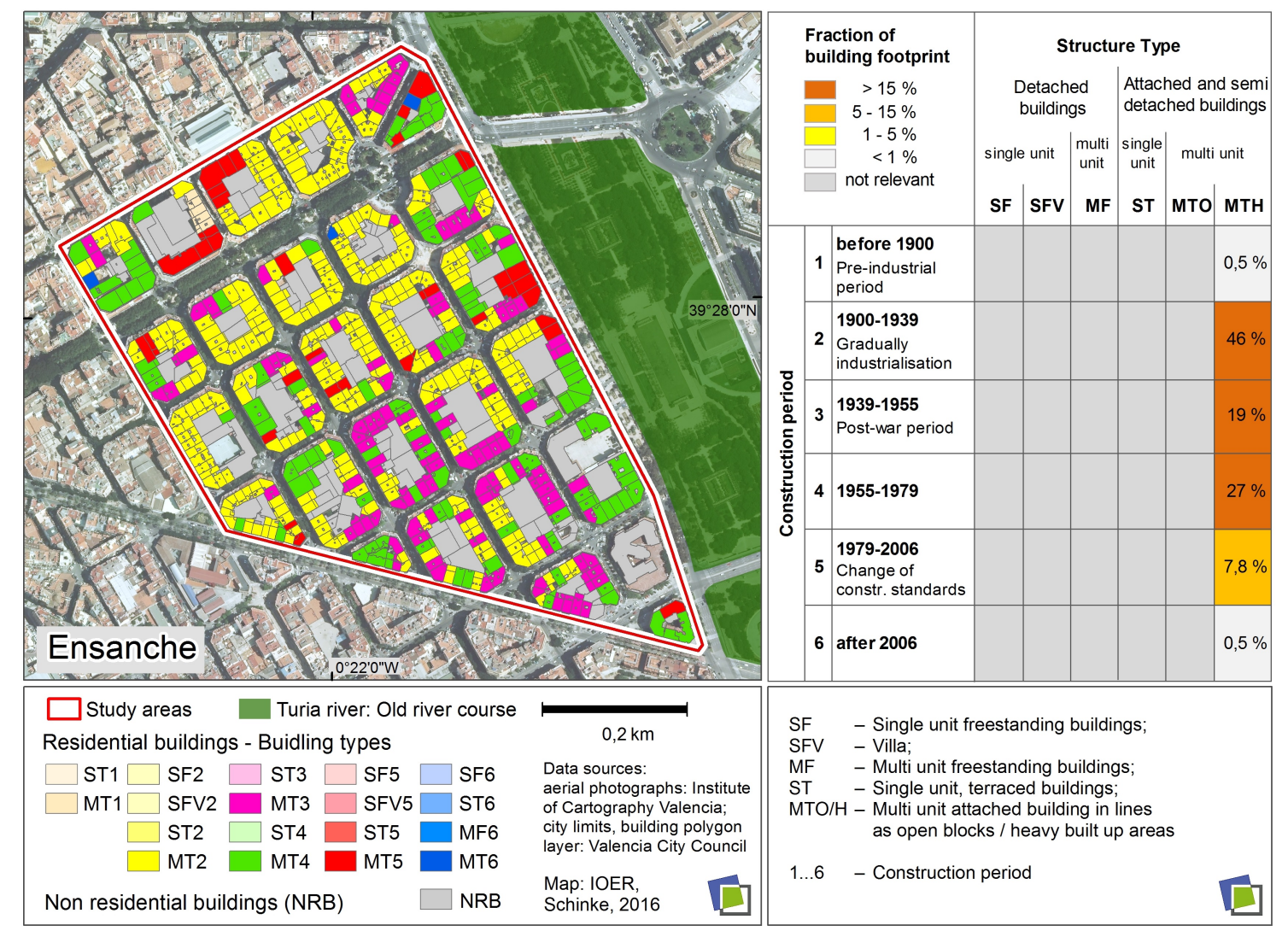

Figure 5. Building type map (left) and Building type matrix (right) of the study area Ensanche.

It illustrates Ensanche as a homogeneous heavily built-up area with around 550 residential buildings. The urban development started at the end of the pre-industrial period (about the 1880s) in the northwest, close to the city centre and was extended stepwise in the southeast direction, away from the city centre. The built up area is comprised of attached multi-unit residential and a few non-residential buildings such as schools, churches and commercial building complexes. The main development phase of the area ended before the 1980s.

\subsection{Flood Vulnerability of Buildings and the Effects of Object-Related FReT}

The derivation of site-specific depth-damage curves is based on the previously described extended synthetic method with a detailed analysis of characteristic, actually existing buildings surveyed in the study area, having regards to well-engineered solutions of FReT. The in-depth analysis of the building type representatives included intensive archive research and on-site inspections in order to 
identify, analyse, and describe the building characteristics regarding their structural design, building materials, and building services. The integration of the FReT effects follows additional methodical steps. Taking into account the characteristics of relevant building types, two ranges of design water levels were specified. The design water level up to $0.9 \mathrm{~m}$ refers to dry proofing strategy and values higher than $0.9 \mathrm{~m}$ refer to a combined strategy considering dry and wet proofing.

Due to big openings in the ground floor level of the multi unit attached buildings (MTH), it is not useful to integrate building aperture technologies in terms of the dry proofing strategy. From an engineering perspective, the recommendations for the building owners focus here on mobile flood protection systems in front of the façade with separate supporting structures and building connections on the property boundaries. In consequence of this design, the selected technology is relatively independent of the neighbourhood and the building type. The flood protection elevation is set to $0.9 \mathrm{~m}$. In comparison to building aperture technologies, the higher value is possible because of the separate supporting structures.

The wet proofing strategy reduces flood damage to buildings by a modification of building construction and building services. In Valencia, beam-column constructions are frequently used as supporting structures in multi-unit attached buildings (MTH/MTO). As a consequence of this, the ground floor is relatively free of load bearing walls and allows a flexible floor plan design. This is the reason why in the majority of cases the measures focus on wall and floor finish layers as well as on central elements of building services. The relocation of highly vulnerable and cost intensive elevator machinery is in this study an important point to reduce flood damage to buildings. The diagrams in Figure 6 present wet proofing effects for two examples (the building type representatives of MTH3 and MTH5), marked by black rectangles and black dashed lines. In addition, the combination of dry and wet proofing effects based on the selected and recommended FReT is shown (red points with red dashed line).

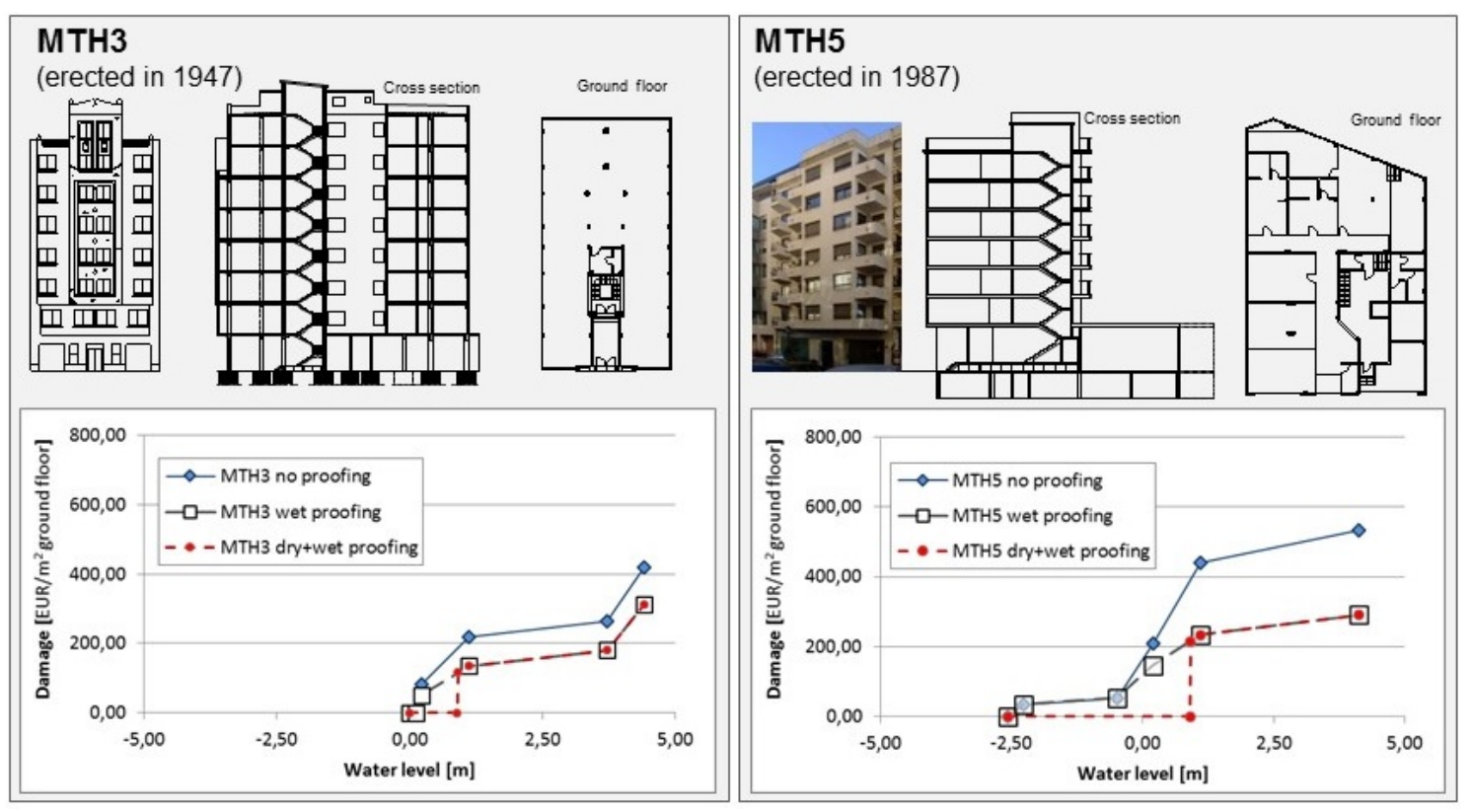

Figure 6. Selected fundamentals and key results of the synthetic vulnerability analysis for two relevant residential building types in the study area Ensanche (source: [43], modified).

Furthermore, damage-relevant data will further reduce the uncertainty of synthetic depth-damage function. In the Valencia case, the land register offers such information like the object-related, lowest basement level [44]. It led to an adaptation of the functions regarding the variation of the basement levels. In Ensanche, this adaptation was possible because of the comparable ground floor height as well as the absence and/or a relative independent location of building service. 
With an extended nomenclature, the function could be allocated to the respective object within the damage model.

\subsection{Damage Modelling}

The preparatory procedures give a set of parameters and input values, which are to be combined in the damage modelling in order to assess the effects of FReT by using a variant analysis. At first, it needs an analysis of the initial conditions considering the design flood without FReT. The results of calculation are shown in Figure 7, which serves as a reference situation. Due to the object based calculation of the exposure and the damage to buildings, the statistical values of the water level minimum, mean, and maximum are provided for every single building polygon. Notwithstanding the water gradient, the statistical values reflect especially the differences of the terrain morphology. Based on this, the affected buildings are differentiated by their exposure using exposure classes (Figure 7, left). The classes are characterised by the highest water level (maximum value of each building), because of safety aspects like a possible overtopping of recommended barriers. In contrast, the damage calculation (Figure 7, right) uses the mean water value as reference value.
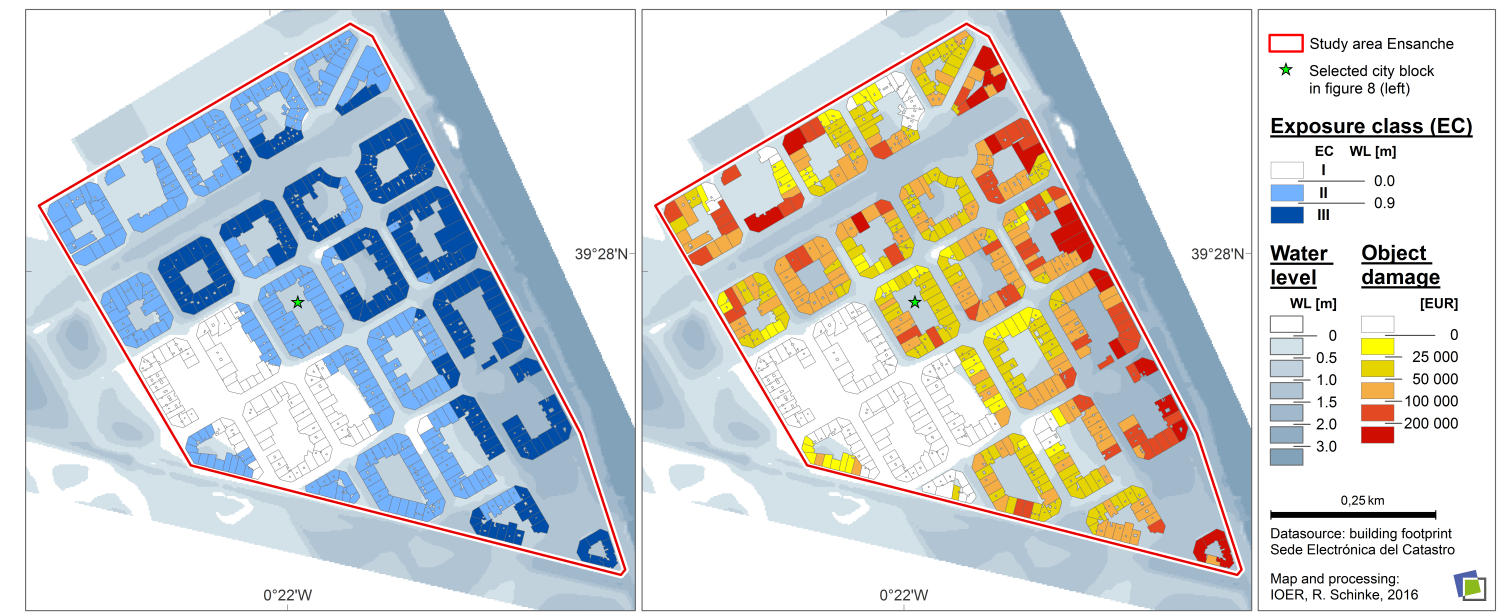

Figure 7. Characterisation of exposure classes based on the design flood (left) and the calculation results of the reference situation with object-related damage to residential buildings (right).

In addition, Figure 7 (left side) illustrates the connection of design water level range and the exposure by derived exposure classes. The exposure class I characterises buildings outside the flood plain area. As a consequence of this, there are no requirements for implementation of FReT. The exposure class II characterises buildings by rated values up to $0.9 \mathrm{~m}$ and the exposure class III marks buildings with water levels, which are higher than $0.9 \mathrm{~m}$. With that in mind, the depth-damage function that includes specific FReT effects can be allocated by the range of design water levels depending on the exposure of the buildings.

The issues regarding the implementation of FReT within the study area Ensanche should give a first insight into possible effects reducing the flood damage to buildings in the future. For this purpose, a rough estimate was used with a range of possible implementation levels (IL). Behind the reference situation, implementation levels of $30 \%$ and $70 \%$ are taken into account. Thereby, the range of $30 \%$ to $70 \%$ is considered as possible for an individual use of FReT in flood risk areas. The reflection of the parameter "implementation level" in the damage modelling was achieved by using weighted depth-damage functions with pre-set percentage values.

In addition, the Monte Carlo simulation (MC) is used here to validate the results achieved with the weight function approach. The MC is a suitable method, because it is not known which individual object will integrate the FReT. The allocation of the FReT was made by object-based random numbers. 
Thereby, the relation of these random numbers are represented by the attribute IL. The results of every MC scenario are based on the statistical evaluation of 500 model runs.

Figure 8a-e (left side) shows selected calculation results for one quarter within the study area Ensanche. The quarter is potentially affected with water levels less than $0.9 \mathrm{~m}$. As a consequence of this, there is no overtopping of the recommended barriers. By comparison with the reference situation (Figure $8 \mathrm{a}$ ), the variant that uses weighted functions leads to an average decrease of the building losses by an increasing implementation level (Figure $8 b, c)$. The variant using MC simulation shows only one single model run (Figure $8 \mathrm{~d}$,e). Therefore, it reflects only one result of a random allocation of the FReT. The objects with FReT reduce the damage to zero due to the installed barrier system in front of the façade. In this context, the increasing implementation level leads to an increasing number of buildings with FReT. The objects without FReT have no loss changes.
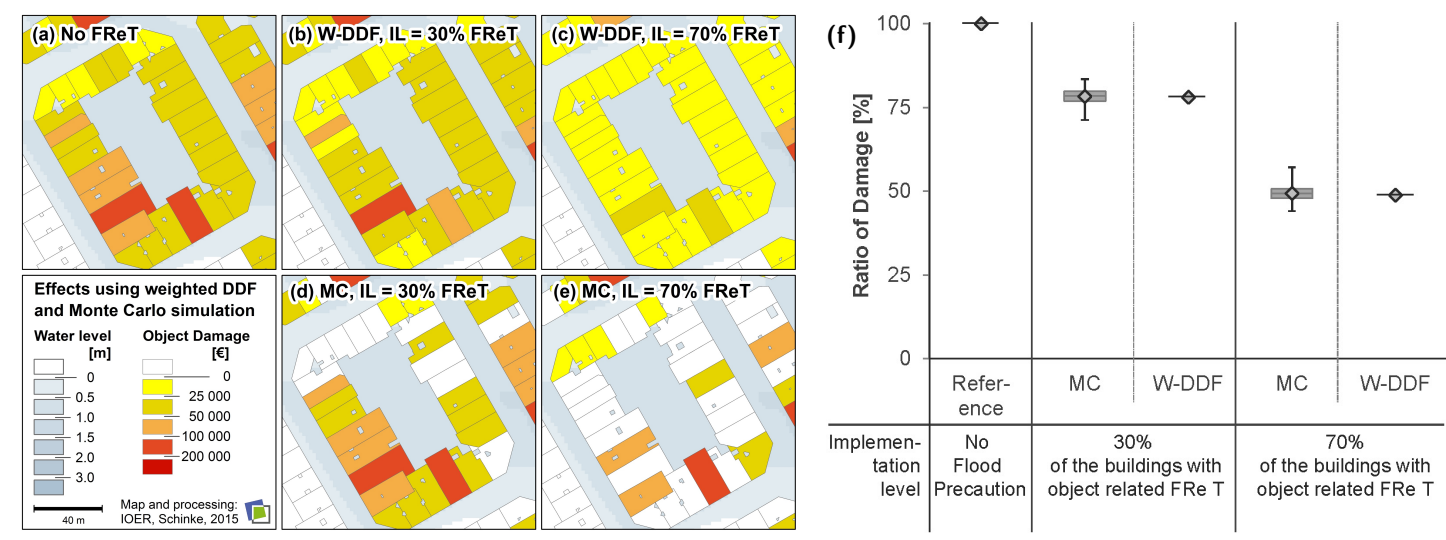

Figure 8. Comparison of the variant analysis using weighted depth-damage function (W-DDF) and Monte Carlo Simulation (MC). Left side: map with one quarter of exposure class II (a): reference situation; (b), (c): W-DDF; (d), (e): example of one model run (MC); Right side: (f) ratio of flood damage to residential buildings in the proofed state to the reference state for the whole case study area.

Figure $8 \mathrm{f}$ (right side) contains a comparison of the variant analysis with a view to the whole study area Ensanche. The results of the MC are shown as box-and-whisker plots. It gives an impression about the distribution of the different simulation runs. It makes clear that the bandwidth is relatively small and the uncertainty is low in consequence of the used approximation to allocate the FReT. The mean values of the MC correlate with the results of the weighted functions. Therefore, both ways appear to be suitable to characterise the effects of FReT.

In general, the results show decreasing flood damage of up to $50 \%$ by an increasing implementation of civil engineering selected and recommended FReT. This gives a basic insight into the opportunity of the private, object-related FReT in the study area. In coordination with any other possible and public mitigation measures, it should lead to well founded and transparent decisions within flood risk management in particular with respect to the selection, location, and design of different systems.

\section{Discussion}

Building-related FReT can be viewed as a smart option to reduce flood damage to buildings and hence to improve the resilience of urban areas. Nevertheless, these potentialities have hardly been used up to now. This can be explained e.g., due to a lack of appropriate tools for both analysing FReT effects on building-scale and transferring these results into a spatial scale of interest. However, such tools are required (i) to improve the understanding of the FReT performance; (ii) to provide a sound foundation for decision-making; as well as (iii) to facilitate FReT implementation. 
Therefore, this paper presents an extended synthetic methodology of a GIS-based damage simulation model in order to analyse the effects of building-related FReT in urban areas. The extended approach covers three methodical key points and is demonstrated in the case study Valencia.

The first key point is aiming at the consideration of object-related FReT in synthetic vulnerability assessments. It becomes clear that detailed investigations of building type representatives with their characteristic building constructions are an appropriate basis to derive well-engineered and optimised solutions to reduce flood vulnerability related to defined ranges of design water levels. Therefore, the resulting set of FReT measures serve as best practise solutions and give valuable ideas for building type based recommendations regarding the implementation of FReT. This will enhance the site-specific information portfolio of key agencies, even if the practical realisation likely needs a verification and adaptation of the recommended solutions with regard to the individual case. Besides this, the analysis allows the derivation of depth-damage functions considering FReT effects as a pre-request for their integration in spatial damage and risk modelling.

The second and third key point transfer the FReT use from individual building into a spatial context. It uses the attribute "implementation level" that reflects the scope of FReT use within the investigation site and adapted the depth-damage functions. This attribute is adequate for both the description of the current situation and the formulation of possible planning objectives. The paper elaborated on the fact that the use of bandwidths is suitable for exhibiting the influence of the parameter on modelling results.

In addition, the third key point focuses on the spatial allocation of the FReT concepts, differentiated by ranges of design water levels. It operates with a spatial classification of buildings regarding their exposure. In this way, the exposures are closely linked with the defined range of design water levels, which refers to a specific set of FReT measures.

The applicability of the extended approach is demonstrated in the case study Valencia (Spain). Notwithstanding the crucial importance of flood hazards in damage modelling, its analysis was not part of the investigation. This is why the estimated flood water levels have a purely hypothetical character, and they serve only as boundary conditions and/or reference values. However, the research is targeted on built environment as receptor and on consequences of floods.

The case study could clarify that the use of the building type approach allows an appropriate differentiation of settlement areas in Spain in order to analyse flood damage to buildings, even if it is only shown for one study area in Valencia with its small size and its homogeneous built-up area. However, the approach covers field surveys and on-sight inspections to collect detailed information about the local building characteristics. Concerning future investigations in larger areas, the analysis of building types can be supported by manual or semi-automatic geo-information systems (see e.g., [45]).

Depending on the built-up area characteristic in Valencia, synthetic depth-damage functions are derived for predominant, site-specific building types. The paper illustrates that the collected engineering knowledge about building constructions and building materials are one major precondition (i) for the stepwise calculation of refurbishment costs as well as (ii) for the selection and implementation of appropriate FReT measures in damage and risk assessments. In the Valencia case, the definition of the design water level is closely linked with flood-resilience strategies. This turned out to be an advantage because the set of FReT measures could be easily associated with the derived ranges of design water levels. Within the Spanish example, the FReT implementation level ranges between $30 \%$ and $70 \%$ covering both a realistic and an optimistic assumption. It resulted in damage reduction up to $50 \%$ within the case study area. In this context, the application of the Monte Carlo approach clarifies the possibilities of a detailed consideration of FReT and validates the weighted function method. In view of the resulting benefits, the investigation deals with an economic valuation of selected FReT measures. Due to a clear description of implemented FReT, their costs can be assessed in the same way and the result open up its evaluation in Cost-Benefit-Analysis (CBA) for individual buildings and for the whole investigation area. 


\section{Conclusions}

In summary, the paper provides insights into the detailed analysis of FReT effects and their integration into damage modelling using a high spatial and contextual resolution. It offers a valuable basis for site-specific derivation of synthetic depth-damage functions and combines in a particular manner engineering studies with innovative tools of geo-information systems. The overall results provide the basis for the application of the modelling approach in other (Spanish) flood risk areas and support the decision making process of key agencies, which will contribute toward a more resilient world.

Acknowledgments: The presented work was part of the research project "SMARTeST—Smart Resilience Technology, Systems and Tools", which is integrated into the European Union's Seventh Framework Programme (Grant agreement no. 244102). We thank the European Commission for the financial support and the Spanish partners for their comprehensive assistance. The collection of data, accompaniment during field surveys, as well as establishing contacts to responsible authorities and professional experts have been very valuable for the success of the work. Regarding this, we would like to mention the cooperation with the Regional and Local Governments of Valencia (Generalitat Valenciana and Valencia Council), Instituto Valenciano de la Edificación (IVE), Universitat Politècnica de València (UPV), as well as the Universidad Politécnica de Madrid (UPM).

Author Contributions: Stephen Garvin and Thomas Naumann were responsible for the research design and supported the drafting of the manuscript. José Santos López-Gutiérrez provided crucial insights regarding the case study design and established the indispensable connections to information and stakeholders. Anna Kaidel, Sebastian Golz, and Reinhard Schinke collected data and analysed the buildings regarding the building typology. In addition, Anna Kaidel analysed the building vulnerability. Reinhard Schinke conceived the concept including the supplementary methodological steps, calculated the flood damage to buildings, and wrote the manuscript. All authors discussed the results and commented on the manuscript at all stages.

Conflicts of Interest: The authors declare no conflict of interest. The European Commission as a public funding agency had no role in the design of the study; in the collection, analyses, and interpretation of data; in the writing of the manuscript and in the decision to publish the results.

\section{References}

1. Veerbeek, W.; Zevenbergen, C. Deconstructing urban flood damages: Increasing the expressiveness of flood damage models combining a high level of detail with a broad attribute set. J. Flood Risk Manag. 2009, 2, 45-57.

2. Naumann, T.; Nikolowski, J.; Golz, S.; Schinke, R. Resilience and resistance of buildings and built structures to flood impacts-Approaches to analysis and evaluation. In German Annual of Spatial Research and Policy 2010: Urban Regional Resilience: How Do Cities and Regions Deal with Change? Müller, B., Ed.; Springer: Berlin/Heidelberg, Germany, 2011; pp. 89-100.

3. Jha, A.; Bloch, R.; Lamond, J. Cities and Flooding-A Guide to Integrated Urban Flood Risk Management for the 21st Century; The World Bank: Washington, DC, USA, 2012.

4. Poussin, J.; Bubeck, P.; Aerts, J.; Ward, P. Potential of semi-structural and non-structural adaptation strategies to reduce future flood risk: Case study for the Meuse. Nat. Hazards Earth Syst. Sci. 2012, 12, 3455-3471.

5. Buckle, P.; Mars, G.; Smale, S. New approaches to assessing vulnerability and resilience. Aust. J. Emerg. Manag. 2000, 15, 8-15.

6. Thywissen, K. Components of Risk-A Comparative Glossary; United Nations University, Institute for Environment and Human Security: Bonn, Germany, 2006.

7. Golz, S.; Schinke, R.; Naumann, T. Assessing the effects of flood resilience technologies on building scale. Urban Water J. 2015, 12, 30-43.

8. Joseph, R.; Proverbs, D.; Lamond, J. Homeowners' perceptions of property-level flood risk adaptation (PLFRA) measures: The case of the summer 2007 flood event in England. Int. J. Saf. Secur. Eng. 2015, 5, 251-265.

9. Serre, D.; Barroca, B.; Laganier, R. Resilience and Urban Risk Management; CRC Press Balkema, Taylor \& Francis Group: London, UK, 2012.

10. Bathrellos, G.; Gaki-Papanastassiou, K.; Skilodimou, H.; Papanastassiou, D.; Chousianitis, K. Potential suitability for urban planning and industry development by using natural hazard maps and geological-Geomorphological parameters. Environ. Earth Sci. 2012, 66, 537-548. 
11. Serre, D.; Barroca, B.; Balsells, M.; Becue, V. Contributing to urban resilience to floods with neighbourhood design: The case of Am Sandtorkai/Dalmannkai in Hamburg. J. Flood Risk Manag. 2016, doi:10.1111/jfr3.12253.

12. Albano, R.; Mancusi, L.; Sole, A.; Adamowski, J. Collaborative strategies for sustainable EU flood risk management: foss and geospatial tools—Challenges and opportunities for operative risk analysis. ISPRS Int. J. Geo-Inf. 2015, 4, 2704-2727.

13. The European Parliament and the Council of the European Union. Directive 2007/60/EC on the assessment and management of flood risks. Off. J. Eur. Union 2007, L.288, 27-34.

14. De Moel, H.; Jongman, B.; Kreibich, H.; Merz, B.; Penning-Rowsell, E.; Ward, P. Flood risk assessments at different spatial scales. Mitig. Adapt. Strateg. Glob. Chang. 2015, 20, 865-890.

15. Connelly, A.; Gabalda, V.; Garvin, S.; Hunter, K.; Kelly, D.; Lawson, N.; O’Hare, P.; White, I. Testing innovative technologies to manage flood risk. Proc. Inst. Civ. Eng. (ICE)—Water Manag. 2015, 168, 66-73.

16. Vojinović, Z. Flood Risk: The Holistic Perspective_From Integrated To Interactive Planning for Flood Resilience; IWA Publishing: London, UK, 2015.

17. Bowker, P. Flood Resistance and Resilience Solutions: An RED Scoping Study; Technical Report; Environment Agency, Department for Environment, Food and Rural Affairs: London, UK, 2007.

18. Escarameia, M.; Tagg, A.; Walliman, N.; Zevenbergen, C.; Anvarifar, F. The role of building materials in improved flood resilience and routes for implementation. In Proceedings of the 2nd European Conference on Flood Risk Management-FLOODrisk2012, Rotterdam, The Netherlands, 19-23 November 2012; pp. 19-23.

19. Escarameia, M.; Walliman, N.; Zevenbergen, C.; de Graaf, R. Methods of assessing flood resilience of critical buildings. Proc. Inst. Civ. Eng. (ICE)—Water Manag. 2016, 169, 57-64.

20. Garvin, S. A Future Flood Resilient Built Environment; BRE Centre for Resilience: Watford, UK, 2014.

21. Department of Communities and Local Government. Development and Flood Risk-Practice Guide, 2nd ed.; British Government: London, UK, 2009.

22. British Standards Institution. BS 85500: 2015 Flood Resistant and Resilient Construction-Guide to Improving the Flood Performance of Buildings—Core Document; Technical Report; British Standards Institution: London, UK, 2015.

23. Australian Building Codes Board. Construction of Buildings in Flood Hazard Areas; Australian Government and States and Territories of Australia: Canberra, Australia, 2012.

24. Gabalda, V.; Garvin, S.; Hunter, K.; Florence, C.; Salagnac, J.L.; Golz, S.; ten Veldhuis, M.C.; Diez, J.; Monnot, J. Flood Resilience Technologies. Deliverable of the EU-FP7 Research Project SMARTeST—Smart Resilience Technology, Systems and Tools. Available online: https://www.ioer.de/1/projekte/ abgeschlossene-projekte/smartest/ (accessed on 14 May 2016).

25. White, I.; Connelly, A.; Garvin, S.; Lawson, N.; O’Hare, P. Flood resilience technology in Europe: Identifying barriers and co-producing best practice. J. Flood Risk Manag. 2016, doi:10.1111/jfr3.12239.

26. Merz, B.; Kreibich, H.; Schwarze, R.; Thieken, A. Review article: Assessment of economic flood damage. Nat. Hazards Earth Syst. Sci. 2010, 10, 1697-1724.

27. Nikolowski, J.; Goldberg, V.; Zimm, J.; Naumann, T. Analysing the vulnerability of buildings to climate change: Summer heat and flooding. Meteorol. Z. 2013, 22, 145-153.

28. Meyer, V.; Becker, N.; Markantonis, V.; Schwarze, R.; van den Bergh, J.; Bouwer, L.; Bubeck, P.; Ciavola, P.; Genovese, E.; Green, C.; et al. Review article: Assessing the costs of natural hazards-State of the art and knowledge gaps. Nat. Hazards Earth Syst. Sci. 2013, 13, 1351-1373.

29. Naumann, T.; Golz, S.; Schinke, R. Parametrisierte synthetische Schadensfunktionen zur Abschätzung hochwasserinduzierter Gebäudeschäden. WasserWirtschaft 2015, 9, 28-32.

30. Kreibich, H.; Christenberger, S.; Schwarze, R. Economic motivation of households to undertake private precautionary measures against floods. Nat. Hazards Earth Syst. Sci. 2011, 11, 309-321.

31. Neubert, M.; Naumann, T.; Deilmann, C. Synthetic Water Level Building Damage Relationships for GIS-Supported Flood Vulnerability Modelling of Residential Properties; In Flood Risk Management_Research and Practice, Proceedings of the European Conference on Flood Risk Management (FLOODrisk 2008), Oxford, UK, 30 September-2 October 2008; Samuels, P., Huntington, S., Allsop, W., Harrop, J., Eds.; CRC Press/Balkema: Leiden, The Netherlands, 2008; pp. 1717-1724.

32. Neubert, M.; Naumann, T.; Hennersdorf, J.; Nikolowski, J. The Geographic Information System-based flood damage simulation model HOWAD. J. Flood Risk Manag. 2016, 9, 36-49. 
33. Schinke, R.; Neubert, M.; Hennersdorf, J.; Stodolny, U.; Sommer, T.; Naumann, T. Damage estimation of subterranean building constructions due to groundwater inundation-The GIS-based model approach GRUWAD. Nat. Hazards Earth Syst. Sci. 2012, 12, 2865-2877.

34. Fleming, G.; Frost, L.; Huntington, S.; Knight, D.; Law, F.; Rickard, C. Learning to Live with Rivers, Final Report of the Institution of Civil Engineers, Presidential Commission to Review the Technical Aspects of Flood Risk Management in England and Wales; Institution of Civil Engineers: London, UK, 2001.

35. Naumann, T.; Nikolowski, J.; Golz, S. Synthetic depth-damage functions-A detailed tool for analysing flood resilience of building types. In Road Map towards a Flood Resilient Urban Environment, Proceedings of the Final Conference of the COST Action C 22 Urban Flood Management in Cooperation with UNESCO-IHP, Paris, France, 26-27 November 2009; Pasche, E., Evelpidou, N., Zevenbergen, C., Ashley, R., Garvin, S., Eds.; TUHH: Hamburg, Germany, 2009.

36. Schinke, R.; Tourbier, J.; Golz, S.; Naumann, T. Guideline for Implementation of Flood Resilience Construction, Technology and Systems. Deliverable of the EU-FP7 Research Project SMARTeST_Smart Resilience Technology, Systems and Tools. Available online: https://www.ioer.de/1/projekte/ abgeschlossene-projekte/smartest/ (accessed on 14 May 2016).

37. Martínez Roda, F. Valencia y las Valencias: Su Historia Contemporánea (1800-1975); Fundación Universitaria San Pablo C.E.U.: Valencia, Spain, 1998.

38. Pastor, F.; Gómez, I.; Estrela, M. Numerical study of the October 2007 flash flood in the Valencia region (Eastern Spain): The role of orography. Nat. Hazards Earth Syst. Sci. 2010, 10, 1331-1345.

39. Silvestre, J.; Diez, J.; López-Gutiérrez, J.; Esteban, M.; UPM SMARTeST-Team. Maritime climate and adaptation to flood events-Some Mediterranean Spanish cases. In Proceedings of the SMARTeST International Conference-Implementing Flood Resilience, Athens, Greece, 27-28 September 2012.

40. Fran Bretones, J. Tecnicas de Rehabilitacion, Soluciones Especificas a las Lesiones Existentes en los Inmuebles del Ensanche de Valencia de 1887. Ph.D. Thesis, Dept. de Construcciones Arquitectonicas, Universidad Politécnica de Valencia, Valencia, Spain, 1990.

41. Instituto Valenciano de la Edificación (IVE). Use of Building Typologies for Energy Performance Assessment of National Building Stock. Existent Experiences in Spain; Technical Report; Instituto Valenciano de la Edificación (IVE): Valencia, Spain, 2011.

42. Serrano Lanzarote, B. (Instituto Valenciano de la Edificación (IVE)). Personal communication, 2011.

43. Kaidel, A. Flood Vulnerability Analysis of Characteristic Building Types in Valencia. Diploma Thesis, TU Dresden, Dresden, Germany, 2012.

44. Gobierno de España, Ministerio de Hacienda y Administraciones Públicas. Sede Electrónica del Catastro. Available online: http:/ / www.sedecatastro.gob.es/ (accessed on 14 September 2014).

45. Hecht, R. Automatische Klassifizierung von Gebäudegrundrissen-Ein Beitrag zur kleinräumigen Beschreibung der Siedlungsstruktur; IÖR-Schriften, Leibniz-Institut für ökologische Raumentwicklung; Rhombos-Verlag: Berlin, Germany, 2014; Volume 63.

(C) 2016 by the authors; licensee MDPI, Basel, Switzerland. This article is an open access article distributed under the terms and conditions of the Creative Commons Attribution (CC-BY) license (http://creativecommons.org/licenses/by/4.0/). 